\title{
Engineering for Social and Environmental Justice: Scaffolding Knowledge during Collaborative Writing Journeys
}

\author{
${ }^{1}$ Wendy Cumming-Potvin, ${ }^{2}$ Caroline Baillie, ${ }^{3}$ John A. Bowden \\ ${ }^{1}$ Murdoch University, ${ }^{2}$ University of Western Australia, ${ }^{3}$ Royal Melbourne Institute of \\ Abstract \\ Technology
}

This paper reports findings of a project titled Engineering Education for Social and Environmental Justice (EESEJ), which was funded by the Australian Learning and Teaching Council. A multidisciplinary research team engaged in a range of activities, such as designing and implementing critical problem solving in undergraduate engineering courses and undertaking collaborative writing. Drawing on the writing journeys of a group of authors in the project, this paper utilizes a multi-dimensional theoretical lens to contribute to discussions for developing socially just engineering education and practice. To illustrate these developmental journeys, the analysis applies Green's [ 1$]$ elaborations about adult learners being scaffolded into new spaces; these spaces are explicated with Vygotsky's zone of proximal development [2], capability theory [3, 4] and the framework of multiliteracies [5]. Data from semi-structured interviews and one co-author's reflections emphasised the concept of co-creation as writing team members scaffolded knowledge. Results highlight the dynamic, recursive and transformative nature of cross-disciplinary learning, which dissipates the dichotomy between experts and novices. The multi-dimensional theoretical lens, which acknowledges the complexity of learning on technical, cognitive and sociocultural levels, can be useful for re-invigorating engineering education and practice for the twenty-first century. Whilst the focus of this paper is limited to the writing journeys of a group of EESEJ participants in authentic professional and informal settings, the interweaving of action, reflection, dependence, independence, rationality and emotion is relevant for the broader spectrum of adult learning. To reinvigorate tertiary curricula and graduate development, highlighting these learning principles may facilitate a reframing of engineering for social and environmental justice, which embraces collaboration, synthesis and reflection from within, and outside the profession [6].

\section{Introduction}

Rapid globalization, expanding environmental issues and societal transformations caused by information technology, have recently placed new demands on engineering education and practice [7]. A technology-focussed globalized society requires engineers who are capable of working across cultural landscapes; thus, engineering practice must shift from traditional problem solving to innovation embedded in complex sociocultural, environmental and ethical issues [8]. This new perspective of engineering should aim to develop engineers who provide technical expertise while being finely attuned to the sociocultural needs of communities [9].

Ironically, in recent years, as the multidimensional aspects of engineering problems have surged, necessitating cross-disciplinary expertise, engineering knowledge has become increasingly compartmentalized in sub-fields such as chemical, civil, mechanical and electrical [10]. These deep and narrow specializations are unhelpful for developing a new approach to engineering education, which views engineering as a holistic way of understanding the world, rather than simply the mastery of maths and science [11]. Although there have been many discussions and some innovative engineering projects in several countries, a new critical approach, which defines engineering as a humanitarian profession for promoting social justice and resisting the traditional focus on corporate profits [12], remains in embryonic form. From this holistic approach, terms such as exploitation, oppression, powerlessness, marginalization and cultural imperialism are addressed [13]. So, whilst costs and procedures must be considered, to act in socially just ways, engineers must responsibly reflect on the complex needs of diverse communities.

In a technology-focused globalized society, the EESEJ project aims to increase tertiary student learning for social and environmental justice through a new critical approach to engineering education, encouraging student engineers to situate their technical expertise and respond ethically in social, economic and environmental contexts, both locally and globally [8]. In Australia, the UK and USA, a multidisciplinary research team engaged in activities, such as designing and implementing critical problem solving in undergraduate engineering courses and undertaking collaborative writing. The EESEJ project is based on several assumptions: that social and environmental justice are interwoven and the holistic curriculum approach recommended by 
Engineers Australia is valid, with students undertaking community projects in ways that responsibly consider social, economic, cultural, environmental and ethical factors. To avoid exploitation, marginalization, cultural imperialism, powerlessness and violence in communities, the work of socially just engineers is integrated with community consultation and governed by antioppressive principles [14].

Obviously, designing engineering programs and practice for social justice can be contentious. Many engineers may possess strong work ethics and an aspiration to help society, but some key structural characteristics of the profession impede work for social justice [6]. For example, society's focus on a military or corporate culture, the engineering profession's privileging of positivist knowledge and the mainstream media's penchant for simplistic explanations of multifaceted social phenomena have hindered understanding between the profession and the general public. In establishing a meeting point between engineering and social justice, a broad question emerges about how engineers can generate a sustainable and socially just future for all [15].

To answer such questions, it is useful to draw on multi-dimensional paradigms which describe engineering education and practice as complex technological artefacts and systems, activities executed with, and for people, and processes interweaving action and thought [16]; these processes include science and maths, but also a range of critical and creative thinking skills. From this perspective, reframing engineering privileges synthesis over analysis, collaborative rather than individual relationships and reflection 'about' as well as 'within' the discipline [17]. In light of this context, the purpose of this paper is to contribute to discussions aiming to develop socially just engineering education and practice, which are embedded in critical thinking and reflective action. First, the theoretical framework used to analyse the EESEJ participants' experiences during collaborative writing activities is explained. This theoretical framework was designed in conjunction with a process evaluation of the EESEJ project, which involved semi-structured interviews and researcher reflections. Second, the research methods of the study are reviewed. Third, selected data from the participants' writing journeys are presented; a focus on one co-author's reflections permits a close exploration of how one participant negotiated crossdisciplinary knowledge in authentic professional and informal settings. Concluding remarks point to the benefits of using a multi-dimensional theoretical lens to elucidate broader learning principles which can contribute to developing socially just engineering education and practice.

\section{Theoretical Framework}

Participants' experiences of the EESEJ collaborative writing activities were analysed through three interwoven theoretical lenses, each concerned with elucidation of learning processes. To illustrate these developmental stories, the analysis in this paper applies Green's [1] elaborations about adult learners being scaffolded into new spaces; these spaces are explicated with Vygotsky's zone of proximal development [2], capability theory [3, 4] and the framework of multiliteracies [5]. This approach underpinned the work of the project writing teams and is used in this paper to analyse interviews with writing team members and one co-author's reflections, with an emphasis on the concept of cocreation.

Vygotsky's zone of proximal development (ZPD). Vygotsky's sociocultural theory [2] suggests that learning is constructed and negotiated through social experiences. Describing the relation between learning processes and capabilities, Vygotsky identified at least two developmental levels, the first involving a learner's actual development and the second measuring the learner's accomplishments with others' assistance. The ZPD identifies the space into which the learner can progress, with help from more experienced peer(s) or expert other(s), and where shared knowledge is constructed and negotiated, prior to being internalized or mastered by the individual learner. In parallel, Wood, Bruner and Ross [18] developed the metaphor of scaffolding to describe the process of graduated assistance as adults support children's problem-solving activities, with steps such as building interest, keeping the child on track, simplifying and/ or demonstrating the task. This original "linear" concept has been replaced by a widened metaphor of scaffolding that emphasises aspects such as temporality, physical context, interdependent and complementary roles of children, caregivers or peers and conflict in the learning process or associated relationships [19, 20]. More recently, Green [1] extended the metaphor to include a multiplicity of processes and key elements in supporting the learning of adults. Inspired by the work of Bowden and Marton [4], Green argued that in such scaffolded learning spaces, the influential expert(s) does not have ready-made answers and supports the learner on a recursive, variable and unknown journey. Describing complex processes when an influential adult supports adult researchers within communities of practice, Green adapted Wood et al.'s original metaphor of scaffolding [18]. She identified key elements, such as: motivating others, balancing dependence with independence, working from individuals' capabilities, engaging in explicit discourses and promoting reflexivity. 
Capability theory and variation theory. Capability theory [3] has been developed to explain the way that experiences of learning content in university programmes can be used by students to develop their capacity to handle previously unseen situations in their professional, social and personal lives. Such capabilities are developed through reflection on experience of variation [4] and include the capacity to discern what are the key aspects of each new situation, what knowledge is relevant, how to design a response and how to implement it. Qualities of discernment and judgement are paramount and the knowledge required and responses devised in most real situations go beyond simple discipline knowledge. So-called generic skill development needs to be integrated with content learning and to be part of capability development. The notion of social justice as a central aspect of all engineering practice is one example of this.

Multiliteracies. Developed by the New London Group [5], this theoretical perspective contends that due to increasing cultural and linguistic diversity and channels of communication, new ways of approaching literacy are required. A multiliteracies' approach aims to support access to evolving forms of language, critical civic engagement and power.

A pedagogy of multiliteracies [5] is underpinned by four components that are interrelated and occur simultaneously in sophisticated ways. Situated practice refers to a component that provides opportunities for risk taking and immerses the learner in their affective and sociocultural experiences. Overt instruction includes scaffolding on the part of the teacher and other experienced learners to allow the learner to focus on explicit features of their learning. Thus, the learner becomes consciously aware of the learning process. Critical framing allows learners to step back from their learning to critique historical, sociocultural and ideological systems of knowledge. Transformed practice permits learners to apply their knowledge, innovate and transfer knowledge to new contexts.

Figure 1, below, provides a visual representation to summarize how the theoretical framework underpinned the participants' collaborative writing journeys. The outside circle represents variation and capability theory $[3,4]$, a pedagogy of multiliteracies [5] and Vygotsky's zone of proximal development [2], which impact significantly on socially constructed learning. The second circle represents the collaborative writing groups, composed of members of the EESEJ research team. The inner circle represents one co-author, whose reflections are captured within the analysis of this paper.

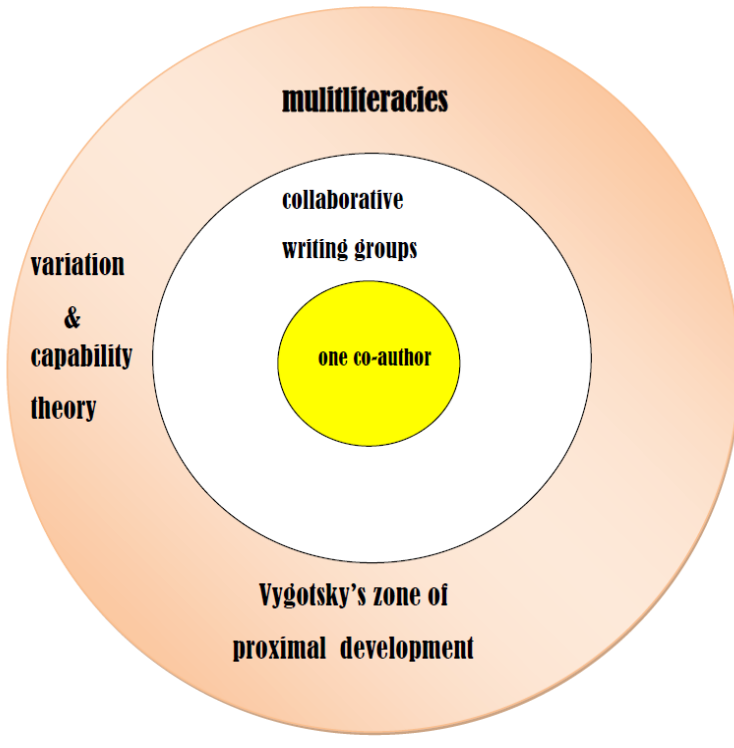

Figure 1. Summary of how the theoretical framework underpinned the participants' collaborative writing journeys

\section{The Study}

As explained in the introduction, the EESEJ project aimed to promote a new critical approach that would enhance engineering students' learning for social and environmental justice. A multidisciplinary research team in Australia, the UK and USA engaged in a range of activities, such as designing and implementing critical problem solving in undergraduate engineering courses. As the research team undertook collaborative writing activities in small groups, to support these tasks, a range of qualitative methods was employed. The qualitative approach was selected as appropriate for examining phenomena from the participants' perspectives [21]. Strategies included reflective journaling, semistructured interviews, and an informal peer-review process involving critical friends.

Once small groups had written drafts of their articles, which were eventually to be submitted for peer-reviewed publication, the texts were sent to the critical friends, who provided informal feedback. At any point during the project, members of the writing groups could keep a reflective journal. The semistructured interviews with the writing groups were generally conducted with pairs of authors who had written together and focused on the following questions: 
- What did authors have in mind when they first thought about the paper?

- What did they anticipate might be the other author's perspective?

- How did the contribution fit with or differ from what was anticipated?

- How did the two of them work out how to write the paper together?

- What was the plan for the paper?

- Did it all work out as planned?

- If not, what actually happened?

- Did either notice any shift in perspective, either for themselves or for their writing partner?

\section{Data Presentation and Analysis}

\subsection{The Interviews}

Data from the interviews link with variation theory and capability development $(3,4)$ and are presented below, drawing on participants' responses to specific questions. The participants' perceptions of the collaborative writing process can be characterized as a trading zone [22], whereby the writers, although drawing on different and perhaps even conflicting ideas, learned to work in an intermediate zone to locally coordinate procedures.

- What was the plan for the paper?

Because of the way the project was set up, almost all of the papers were planned around the nonengineering perspective. A particular aspect was identified and then the exploration of that idea was undertaken with a focus on implications for support of engineers in their work towards social justice. In several papers, a case-study approach was the central planning feature while in others a particular theoretical framework was the defining feature.

- Did it all work out as planned? If not, what actually happened?

Once the planning had been done, the process was completed as planned in most cases. As anticipated, specific authors did the bulk of the writing in some cases while, in others, transcripts were made of meetings and these led to joint development of a manuscript. In all cases, all authors gave feedback on any written material and added further written pieces.
Hence while there was considerable variation in the relative contributions of authors from team to team, none of it was unforeseen and the content of the paper had developed as planned. No one expressed any dissatisfaction with the way it all had happened. Indeed several authors explicitly commented on the value of the experience to them and wished it were not so rare. Some talked positively about learning to write in a new and different way.

- Did either of you notice any shift in perspective for either of you?

At the most basic level, a number of authors were pleasantly surprised to see their colleague's openness to other ideas, thereby implicitly indicating that they had anticipated some difficulties with this. Most authors spoke about changes in their own ways of seeing. Some spoke about how their own frameworks had been expanded by the experience and they looked forward to doing more work beyond the paper. At the very least, most authors saw considerable value in looking at familiar issues from the perspective of another discipline. Few spoke at any length about changes in perspective of their coauthor except for those few who engaged in the mutual development of a new, integrated framework.

Here, it can be argued that through the trading zone [22], the participants were able to act capably in authentic professional settings by negotiating knowledge, thereby breaking down crossdisciplinary boundaries [4]. As the learners shared problem-solving [20] and negotiated interactions, a cognitive shift developed, leading through Vygotsky's zone of proximal development [2].

\subsection{The Reflections of One Co-Author}

To more closely explore the negotiation of crossdisciplinary knowledge in authentic professional settings, the passages below were selected from one co-writer's reflections at various stages of the collaborative writing process. At the beginning of the process, when the larger group brainstormed ideas about content for the publications, this participant commented:

Above all, we were led in a way that allowed us to voice opinions, agree, disagree, offer constructive feedback, etc. Decisions about ways to move forward as a team were negotiated, transparently. ...those present were encouraged to offer suggestions, critique, comment, etc. I was struck by the similarities across disciplines as academics recounted the challenges of teaching in their respective fields... 
My experiences in my own discipline resonated with those in engineering education:

- How can we promote reflection across our student cohorts?

- How can we move beyond quick-fix recipes to promote critical reflection in action?

- How do we encourage our students to examine professional situations from multiple perspectives?

The participant's mention of agreement, disagreement and critique, in conjunction with crossdisciplinary comparisons about tertiary students' reflection, points to the importance of adults engaging in explicit discourse to support their learning [1]. This explicit discourse allows learners to draw on their prior knowledge, suggesting an immersion in 'situated practice' [5]. While the participant refers to leadership, the focus on peer discussions alludes to a widened metaphor of scaffolding, moving beyond the expert-novice divide to include the complementary role of peers in adult learning [19].

As the collaborative writing process evolved, to scaffold cross-disciplinary learning, the participant appears to strike a balance between independence and dependence [1]:

...to take advantage of cross-disciplinary expertise, the main curriculum group was divided into smaller teams. Face-to-face discussions, telephone conversations and draft texts (sent via email) formed part of the writing strategies to solidify writing partnerships. As ever, the writing process was recursive and dynamic. Upon reflection, the relentless motion of writing is captured by a rolling image of children propelling a seesaw to and fro in the wind. There is fleeting elation as one sails up and rests momentarily balanced in mid-air.

For me, these 'eureka' moments surfaced surprisingly as I independently explored particular written texts. Specific texts offered a complicity of ideas about social justice and critical pedagogy that encouraged me to tentatively transfer understandings from liberal arts to engineering education. Then, as the seesaw hit the ground, my feet covered heavily with sand, I felt very confused by the massive information overload associated with academic writing.

At times, I could feel myself being seduced by unrealistic aims, such as the temptation to endlessly 'read just one more article' to perfect my understandings. But the draft text needed to be drawn together, with precision and focus-all within a strict word count and time frame. The key questions became:
- Where to cut?

- How to synthesize?

- Where to focus?

In the above extract, the participant increases their zone of proximal development [2] by employing diverse learning strategies. While peer interaction is interwoven early in the passage, the role of independent learning is increasingly highlighted. Through retrospective reflection, the participant visualizes the writing process as equally exhilarating and overwhelming. This gamut of emotions suggests 'situated practice' [5] as the participant acknowledges how individuals' affective factors impact on learning. Moreover, as the writing process unfolds, the participant discusses the role of specific texts in facilitating the tentative transfer of knowledge between disciplines; this capacity to construct knowledge in new contexts points to the aspect of 'transformed practice' [5].

In the following extract, as the writing process progresses, the participant appears to reflect more specifically on how to improve the text. Drawing on a cycle of reflection and action, the participant uses personal judgment to seek informal advice from peers regarding key aspects of the content [3, 4]. Thus, although the critical friends' expertise appears fundamental to improving the technical aspects of the text, the participant uses professional judgment to drive the consultation process.

...the way forward to enhance text revisions emerged through the commentary of critical friends. Approximately mid-point in the process, writing partnerships were encouraged to send works in progress for informal critical review. Once this informal and constructive feedback was received, I felt relieved. Although the draft text still needed revision, the critical friend's words of encouragement provided momentary equilibrium so that the seesaw balanced in mid-air.

After partnership consultations, I perused the revisions with renewed energy, leading me to informally consult critical friends, such as those practicing professionally and/or studying in engineering. On one occasion, after reading the most recent version of the draft publication, a critical friend simply asked me: What is the story? This question encouraged me to systematically review all sections of the text to seek a logical way to 'tell the story'.

On another occasion, a critical friend spent time responding to my questions so that I could better understand some technical aspects of engineering, such as structural processes in mining. 
So, to tell the required 'story', the participant works from individual capabilities within a liberalarts' based discipline to engage in explicit discourses with critical friends possessing technical expertise in engineering and ultimately move through Vygotsky's zone of proximal development [2].

\section{Concluding Remarks}

Examining participants' experiences of the EESEJ collaborative writing activities has underscored the dynamic, recursive and transformative nature of cross-disciplinary learning processes. In this case, the participants' developmental stories about being scaffolded into new spaces were elucidated through three theoretical lenses, namely Vygotsky's zone of proximal development [2], capability theory [3, 4] and the framework of multiliteracies [5]. Data from the semi-structured interviews with writing team members and one co-author's reflections emphasised the concept of co-creation as participants negotiated and constructed knowledge in a trading zone [22]. The notion of reflection in action became primordial in this trading zone while one co-author broke down cross-disciplinary boundaries by seeking informal advice from critical friends.

As this participant increased their zone of proximal development [2], the complementary role of peers became particularly important for transforming knowledge from liberal arts to engineering. While cross-disciplinary boundaries dissipated in a writing process interwoven with solitary and social learning, so did the dichotomy between expert and novice learners.

This multi-dimensional theoretical lens, which acknowledges the complexity of learning on technical, cognitive and sociocultural levels, can be useful for re-invigorating engineering education and practice for the twenty-first century. As globalization, migration and computer-related technology impact on contemporary society, engineering challenges have become increasingly complex and embedded in sociocultural issues [7]. Consequently, in response to increasingly complex technical issues, which are embedded in community disquiet over issues such as poverty, sustainability and education, new paradigms of engineering would be well placed seek balance between technical expertise, economic steadiness and socially just endeavours.

The focus of this article is limited to the writing journeys of a group of EESEJ participants who scaffolded their knowledge through crossdisciplinary trading [22] in authentic professional and informal settings. Still the significance of interweaving action with reflection, dependence with independence and rationality with emotion is relevant for the broader spectrum of adult learning. To revitalize tertiary curricula and graduate development, accentuating these learning principles may facilitate a reframing of engineering for social and environmental justice, which embraces collaboration, synthesis and reflection from within, and outside the profession [6].

\section{References}

[1] Green, P. (2005). Spaces of influence: A framework for analysis of an individual's contribution within communities of practice Higher Education Research \& Development 24 (4), pp. 293-307

[2] Vygotsky, L. (1978). Mind in society. Cambridge, MS: Harvard University Press

[3] Bowden, J.A. (2004). Capabilities-driven curriculum design. In Eds. C. Baillie \& I. Moore, Effective Teaching and Learning in Engineering (pp 36-47). London: Kogan Page.

[4] Bowden, J.A. \& Marton, F. (1998). The University of Learning: Beyond Quality and Competence. London: Kogan Page

[5] The New London Group (1996). A pedagogy of multiliteracies: Designing social futures. Harvard Educational Review 66(1), 60-92 http://wwwstatic.kern.org/filer/blogWrite44ManilaWebsite /paul/articles/A_Pedagogy_of_Multiliteracies_Designing Social_Futures.htm (accessed 26/4/11)

[6] Tucker, J., Pawley, A. Riley, D. \& Catalano, G. (2008). Special Session- New Engineering Stories: How Feminist Thinking can Impact Engineering Ethics and Practice. $38^{\text {th }}$ ASEE/IEEE Frontiers in Education Conference (F3J-1) Oct. 22-25, Saratoga Springs, NY

[7] Klawe, M. (2010). In Eds. D. Grasso \& M. Brown Burkins. Holistic Engineering. Beyond Technology. (Forward, p. xiii). New York: Springer Science and Business Media.

[8] Duderstadt, J. (2010). Engineering for a Changing World: A Roadmap to the future of American Engineering Practice, Research, and Education. In Eds. D. Grasso \& M. Brown Burkins. Holistic Engineering. Beyond Technology. (pp. 17- 35). New York: Springer Science and Business Media.

[9] Riley, D. (2008). Engineering and Social Justice. San Rafael, California, USA: Morgan \& Claypool.

[10] King, J. (2010) In Eds. D. Grasso \& M. Brown Burkins. Holistic Engineering. Beyond Technology. Forewards (pp vii-viii). New York: Springer Science and Business Media.

[11] Miller, R. (2010). In Eds. D. Grasso \& M. Brown Burkins. Holistic Engineering. Beyond Technology. Forewards (pp xi-xii). New York: Springer Science and Business Media 
[12] Baillie, C. (2006). Engineers within a local and global society. Synthesis lectures on Engineers, technology and society. Lecture (\#2). Series Editor: C. Baillie. Queen's University. Morgan \& Claypool.

[13]Young, I. (2000). Five Faces of Oppression. In Eds. M. Adams, X. Zuniga, C. Rose Castaneda, M. L. Peters, H.W. Hackman, and W. J. Blumenfeld, Readings for Diversity and Social Justice, (pp.35-49). New York: Routledge.

[14] Baillie, C. \& Catalano, G. (2009). Engineering and Society. Working Towards Social Justice Morgan \& Claypool (www.morganclaypool.com). Series Editor, C. Baillie, Synthesis Lectures on Engineers, Technology and Society.

[15] Pritchard, J. \& Baillie, C. (2006). How can engineering education contribute to a sustainable future? European Journal of Engineering Education 31(5), 555565

[16] Goldberg, D. (2010). The Missing Basics and other philosophical reflections for the transformation of engineering education. In. Eds. In Eds. D. Grasso \& M. Brown Burkins. Holistic Engineering. Beyond Technology. (pp. 145-165). New York: Springer Science and Business Media.

[17] Tucker, J., Pawley, A. Riley, D. \& Catalano, G. (2008). Special Session- New Engineering Stories: How Feminist Thinking can Impact Engineering Ethics and Practice. $38^{\text {th }}$ ASEE/IEEE Frontiers in Education Conference (F3J-1) Oct. 22-25, Saratoga Springs, NY

[18] Wood, D., Bruner, J., \& Ross, G. (1976). The role of tutoring in problem solving. Journal of Psychology and Psychiatry. 17(2), 89-100.

[19] Cumming-Potvin, W. Renshaw, P. \& van Kraayenoord, C. (2003). Scaffolding and bilingual shared reading experiences: Promoting primary school students' learning and development. Australian Journal of Language and Literacy 26(2), 54-68.

[20] Rogoff, B. (1990). Apprenticeship in thinking. Cognitive development in social context. New York: Oxford University Press.

[21] Ary, D. L. Jacobs, Razavieh, A., \& Sorensen, C. (2006). Introduction to Research Methods. $7^{\text {th }}$ Edition. Belmont, California, USA: Thomson Wadsworth

[22] Galison, P. (1997). Image and Logic: A material culture of microphysics, Chicago: University of Chicago Press. 